\title{
Assessing the impact of vertical heat exchangers on the response of a retaining wall
}

\author{
Eleonora Sailer ${ }^{1, *}$, David M. G. Taborda ${ }^{1}$, Lidija Zdravkovic ${ }^{1}$ and David M. Potts ${ }^{1}$ \\ ${ }^{1}$ Imperial College London, Department of Civil and Environmental Engineering, SW7 2AZ London
}

\begin{abstract}
Shallow geothermal energy systems, e.g. borehole heat exchangers or thermo-active structures, provide sustainable space heating and cooling by exchanging heat with the ground. When installed within densely built urban environments, the thermo-hydro-mechanical (THM) interactions occurring due to changes in ground temperature, such as soil deformation and development of excess pore water pressures, may affect the mechanical behaviour of adjacent underground structures. This paper investigates the effects of vertical heat exchangers installed near a deep basement by performing fully coupled THM finite element analyses using the Imperial College Finite Element Program. Different heat exchanger configurations are considered and their influence on the response of the basement wall is assessed in two-dimensional plane strain analyses, where different methods of modelling the heat sources in this type of analysis are employed to evaluate their effect on the temperature field and the non-isothermal soil response.
\end{abstract}

\section{Introduction}

Ground Source Energy Systems (GSESs), such as borehole heat exchangers or thermo-active structures, are able to provide sustainable and low-cost heating and cooling and their use has noticeably increased in the last decades [1]. However, the installation of GSESs in densely built environments may affect the structural response of existing or new underground structures built in their vicinity. Indeed, a change in ground temperatures may lead to soil deformations and the development of excess pore water pressures $[2,3]$, which, in turn, can contribute to movements and changes in forces in nearby structures.

Several studies have focussed on the effect of the heat exchange on the mechanical performance of thermoactive structures, i.e. structures used as heat exchangers, such as foundation piles (e.g. [4, 5]) and retaining walls (e.g. $[6,7,8]$ ). Conversely, little attention has been given to the response of underground structures built in the vicinity of GSESs. Furthermore, limited literature exists on monitoring data of ground temperatures around GSESs. Hence, it is considered important to evaluate the possible implications of the use of ground heat exchangers to the stability and serviceability of nearby underground structures.

This paper investigates, through fully coupled thermohydro-mechanical (THM) analyses carried out using the Imperial College Finite Element Program (ICFEP [9, $10]$ ), the response of a deep basement wall next to which a hypothetical GSES is installed. Particular focus is given to the analysis of the impact of different geometric configurations of vertical ground heat exchangers (VHEs) and the influence of the modelling approach employed to simulate heat sources in two-dimensional plane strain finite element (FE) analyses. Furthermore, this study aims at identifying the THM interactions occurring as a consequence of the changes in ground temperature and their influence on the response of the basement wall.

\section{Numerical analysis}

\subsection{Problem description}

The effect of two different types of vertical ground heat exchangers (VHEs), namely borehole heat exchangers (BHEs) and thermo-active piles (THPs), on the mechanical response of a deep basement wall located in London, is analysed. The geometry of the basement is described in [11] and consists of a $60.0 \mathrm{~m}$ wide excavation supported either side by an $18.0 \mathrm{~m}$ deep and $0.8 \mathrm{~m}$ thick diaphragm wall, a $1.5 \mathrm{~m}$ thick base slab and three $0.35 \mathrm{~m}$ thick floor slabs. The ground profile, together with the initial pore water pressure and $\mathrm{K}_{0}$ distributions, is depicted in Fig. 1 (a) and (b), respectively [8, 12]. The initial temperature is assumed to be $13^{\circ} \mathrm{C}$.

Two different configurations for the VHEs are considered: a square configuration of $6 \times 6$ BHEs, $67.0 \mathrm{~m}$ in length and spaced $6.0 \mathrm{~m}$ apart, and a square pile group consisting of $6 \times 6$ THPs, $25.0 \mathrm{~m}$ deep, $1.0 \mathrm{~m}$ in diameter and with a centre-to-centre spacing of $4.0 \mathrm{~m}$. The nearest VHE in each of these groups is located $5.0 \mathrm{~m}$ away from the right-hand side wall of the basement.

\subsection{Modelling procedure}

Plane strain, fully coupled thermo-hydro-mechanical FE analyses were performed using ICFEP. These simulate the transient phenomena taking place within the soil due to

\footnotetext{
Corresponding author: eleonora.sailer13@imperial.ac.uk
} 
changes in temperature, such as thermal expansion and excess pore water pressure generation and dissipation $[5$, 10]. The finite element mesh extends horizontally $100 \mathrm{~m}$ either side of the basement walls and vertically $60 \mathrm{~m}$ below the toe of the walls. It consists of eight-noded quadrilateral elements, with displacement and temperature degrees of freedom at each node. The elements discretising consolidating materials (i.e. London Clay (LC) and Lambeth Group Clay (LGC)) also have a pore pressure degree of freedom at the corner nodes.

Concrete was modelled as a linear-elastic material. The Made Ground (MG) and Chalk (CH) were modelled as linear elasto-plastic with a Mohr-Coulomb failure criterion. For the remaining soil layers, a Mohr-Coulomb failure criterion coupled with the IC.G3S non-linear elastic stiffness model [13] was adopted. The permeability, $k$, of the consolidating materials was assumed to vary with mean effective stress, $p^{\prime}$, according to:

$$
k=k_{0} e^{-B p^{\prime}}
$$

where $k_{0}$ and $B$ are model parameters, equal to $1 \times 10^{-10} \mathrm{~m} / \mathrm{s}$ and 0.023 , respectively (see [5]).

The mechanical, hydraulic and thermal properties where adopted from [5, 14], with the latter listed in Table 1. For the consolidating materials (LC and LGC), a coefficient of thermal expansion of water of $6.9 \times 10^{-5}$ $\mathrm{m} / \mathrm{mK}$ was employed.

The construction sequence of the basement, as well as the mechanical and hydraulic boundary conditions applied to the FE model are described in [8, 12]. The thermal boundary conditions consist of imposing a no change in temperature at the ground surface, while all other boundaries are considered to be insulated. It should be noted that before the activation of the VHEs, the excess pore water pressures generated during the construction stages of the retaining wall were fully dissipated. This allows the thermal effects to be considered in isolation. Once hydraulic equilibrium was reached, one year of operation of the VHEs was modelled (see section 2.3).

Table 1. Thermal material properties (after $[5,14])$

\begin{tabular}{|c|c|c|c|}
\hline Material & $\begin{array}{c}\text { Coefficient } \\
\text { of thermal } \\
\text { expansion } \\
\alpha \\
{[\mathrm{m} / \mathrm{mK}]}\end{array}$ & $\begin{array}{c}\text { Thermal } \\
\text { conductivity } \\
\lambda \\
{[\mathrm{kW} / \mathrm{mK}]}\end{array}$ & $\begin{array}{c}\text { Volumetric } \\
\text { specific } \\
\text { heat } \\
\text { capacity } \\
\rho c \\
{\left[\mathrm{~kJ} / \mathrm{m}^{3} \mathrm{~K}\right]}\end{array}$ \\
\hline Concrete & $8.5 \times 10^{-6}$ & $2.33 \times 10^{-3}$ & 1920 \\
\hline $\begin{array}{c}\text { Made Ground } \\
\text { (MG) }\end{array}$ & $1.7 \times 10^{-5}$ & $1.40 \times 10^{-3}$ & 1900 \\
\hline $\begin{array}{c}\text { Terrace Gravel } \\
\text { Deposit (TGD) }\end{array}$ & $1.7 \times 10^{-5}$ & $1.40 \times 10^{-3}$ & 1900 \\
\hline $\begin{array}{c}\text { London Clay } \\
\text { (LC) }\end{array}$ & $1.7 \times 10^{-5}$ & $1.79 \times 10^{-3}$ & 1820 \\
\hline $\begin{array}{c}\text { Lambeth } \\
\text { Group Clay } \\
\text { (LGC) }\end{array}$ & $1.7 \times 10^{-5}$ & $2.20 \times 10^{-3}$ & 1760 \\
\hline $\begin{array}{c}\text { Thanet Sand } \\
\text { (TS) }\end{array}$ & $1.7 \times 10^{-5}$ & $2.40 \times 10^{-3}$ & 1760 \\
\hline Chalk (CH) & $1.7 \times 10^{-5}$ & $2.00 \times 10^{-3}$ & 2750 \\
\hline
\end{tabular}

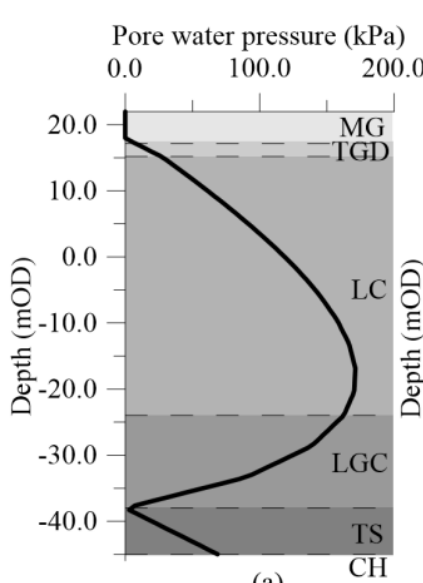

(a)
$\mathrm{K}_{0}$

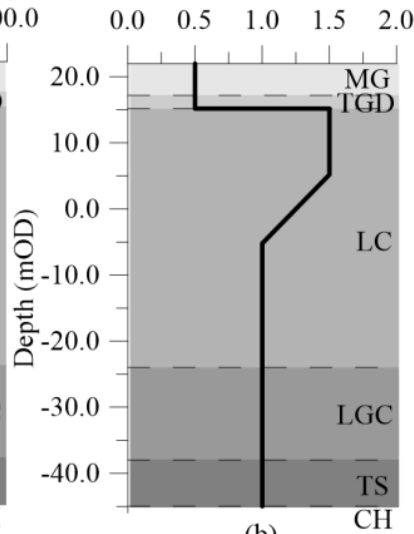

(b)
Fig. 1. Initial ground conditions (a) pore water pressure and (b) $\mathrm{K}_{0}$ profile

\subsection{Vertical heat exchangers}

The vertical heat exchangers were modelled in 2D plane strain analyses by applying a heat flux boundary condition, either along a line (for BHEs) or over a 2D area (for THPs) at the location of the heat sources. One year of operation, where the heat exchangers work for six months in cooling mode (i.e. heat injection) and six months in heating mode (i.e. heat extraction), is simulated.

The heat exchange rate of each individual VHE, $q_{V H E}$, was assumed to be $27.0 \mathrm{~W} / \mathrm{m}$, which is within the range suggested by design guidelines (e.g. [15]). Due to the twodimensional (2D) nature of the analysis, an equivalent heat flux, $q_{2 D}$, was applied following the procedure outlined by [16]:

$$
\begin{gathered}
q_{2 D, B H E}=T^{*} q_{V H E} / s \\
q_{2 D, T H P}=T^{*} q_{V H E} /(s \cdot d)
\end{gathered}
$$

where $s$ is the out-of-plane spacing [m], $d$ is the pile diameter $[\mathrm{m}]$ and $T^{*}$ is a dimensionless correction factor given by:

$$
\begin{gathered}
T^{*}=1-\frac{1}{1+a \cdot e^{b \cdot n_{o}}} \\
a=a_{1} \ln (\bar{s})+a_{2} \\
b=b_{1} \cdot \bar{s}+b_{2} \\
a_{2}=a_{2,1} \cdot n_{i}+a_{2,2} \\
b_{1}=b_{1,1} \cdot n_{i}+b_{1,2} \\
b_{2}=b_{2,1} \cdot n_{i}+b_{2,2} \\
a_{1}=\left[\left(\beta e^{\gamma \cdot \bar{\lambda}}\right) \cdot \bar{H}^{\delta \cdot \bar{\lambda}+\varepsilon}\right] \\
a_{2,2}=[(\zeta \cdot \ln (\bar{\lambda})+\eta) \cdot \bar{H}+(\theta \cdot \ln (\bar{\lambda})+\iota)] \\
b_{1,2}=\sigma \cdot \bar{\lambda}+\omega \\
b_{2,2}=\left[(\kappa \cdot \ln (\bar{\lambda})+\mu) \cdot \bar{H}^{v \cdot \ln (\bar{\lambda})+\xi}\right]
\end{gathered}
$$

where $n_{o}$ is the number of VHEs in the out-of-plane direction, $n_{i}$ is the number of VHEs in the in-plane direction, $\bar{s}=s / l_{\text {ref }}$ is the normalised spacing ( $s$ is the spacing between the VHEs [m] and $l_{\text {ref }}$ is a reference 
length equal to $1.0 \mathrm{~m}), \bar{H}=H / l_{\text {ref }}$ is the normalised length ( $H$ is the length of the VHEs $[\mathrm{m}]), \bar{\lambda}=\lambda / \lambda_{\text {ref }}$ is the normalised thermal conductivity ( $\lambda$ is the ground thermal conductivity $[\mathrm{W} / \mathrm{mK}]$ and $\lambda_{\text {ref }}$ is a reference thermal conductivity equal to $1.0 \mathrm{~W} / \mathrm{mK}$ ), while $a_{2,1}, b_{1,1}, b_{2,1}, \beta$, $\gamma, \delta, \varepsilon, \zeta, \eta, \theta, \iota, \kappa, \mu, v, \xi, \sigma$, and $\omega$ are constants, the values of which are listed in the table below.

Table 2. Constants for calculation of $T^{*}$

\begin{tabular}{|c|c|c|c|c|c|}
\hline$a_{2,1}$ & -0.0045 & $\varepsilon$ & -0.5187 & $\mu$ & 0.1485 \\
\hline$b_{1,1}$ & 0.0004 & $\zeta$ & 0.0004 & $v$ & 0.1056 \\
\hline$b_{2,1}$ & -0.0042 & $\eta$ & 0.0007 & $\xi$ & -0.2207 \\
\hline$\beta$ & 0.4087 & $\theta$ & -0.1984 & $\sigma$ & -0.0293 \\
\hline$\gamma$ & 0.4571 & $\iota$ & 0.1911 & $\omega$ & 0.1131 \\
\hline$\delta$ & 0.0239 & $\kappa$ & 0.0520 & \multicolumn{1}{|c}{} \\
\cline { 1 - 4 }
\end{tabular}

It is important to highlight that the conventional approach of calculating the equivalent heat flux in $2 \mathrm{D}$ plane strain analyses (i.e. dividing $q_{V H E}$ by the out-ofplane spacing, as is common practice, e.g. [17]), which essentially corresponds to adopting $T^{*}$ equal to 1.0 , predicts higher changes in temperature than those obtained in equivalent 3D analyses. Thus, $T^{*}$ is generally less than 1.0, providing therefore a reduction in the heat flux applied in 2D analyses and improving noticeably the prediction of temperature changes, especially for small groups of VHEs (i.e. small $n_{o}$ ), with small spacing $(s)$ and short length $(H)$ [16].

For the analysed problem, the value of $T^{*}$ is equal to 0.82 for the group of BHEs and 0.73 for the group of THPs, where a weighted average of the soil conductivity based on the thickness of each layer was employed in equations 10 to 13 . Table 3 summarises the characteristics of the VHEs, both with and without the application of $T^{*}$. The heat exchangers were assumed to be operating for a full year and a balanced load was applied (i.e. 6 months of heat injection $-q_{2 D_{-} i}-$ followed by 6 months of heat extraction $\left.-q_{2 D_{-} e}\right)$. Note that in Table 3 , positive numbers refer to energy being injected into the ground.

Table 3. Characteristics of the simulated vertical heat exchangers

\begin{tabular}{|c|c|c|c|c|c|}
\hline \multirow[b]{2}{*}{ Analysis } & \multirow{2}{*}{$\begin{array}{c}H \\
{[\mathrm{~m}]}\end{array}$} & \multirow[b]{2}{*}{$\begin{array}{c}S \\
{[\mathrm{~m}]}\end{array}$} & \multirow[b]{2}{*}{$\begin{array}{c}q_{V H E} \\
{[\mathrm{~W} / \mathrm{m}]}\end{array}$} & $q_{2 D_{-} i}$ & $q_{2 D_{-} e}$ \\
\hline & & & & \multicolumn{2}{|c|}{$\begin{array}{l}{\left[\mathrm{W} / \mathrm{m}^{2}\right] \text { for BHE }} \\
{\left[\mathrm{W} / \mathrm{m}^{3}\right] \text { for } \mathrm{THP}}\end{array}$} \\
\hline $\mathrm{BHE} T^{*}$ & 67.0 & 6.0 & 27.0 & 3.70 & -3.70 \\
\hline BHE & 67.0 & 6.0 & 27.0 & 4.50 & -4.50 \\
\hline THP $T^{*}$ & 25.0 & 4.0 & 27.0 & 4.90 & -4.90 \\
\hline THP & 25.0 & 4.0 & 27.0 & 6.75 & -6.75 \\
\hline
\end{tabular}

\section{Results of the analyses}

The effect of the VHEs on both the soil behaviour and the response of the retaining wall closest to the VHE field is analysed at the end of the period of heat injection (after six months) and at the end of the period of heat extraction (after one year). Furthermore, the impact of modelling the VHEs with and without the application of the correction factor $T^{*}$ is evaluated. In the following sections, the sign convention is such that positive values refer to: tensile axial forces; bending moments as a consequence of tension on the excavated side; upwards vertical movements; horizontal movements towards the retained side and compressive pore water pressures.

\subsection{Soil behaviour}

\subsubsection{Temperatures and pore water pressures}

The contours of temperature changes and excess pore water pressures after 6 months of heat injection for both BHEs and THPs are depicted in Fig. 2, for the cases with $T^{*}$ only. Larger temperatures are registered for the analysis with thermo-active piles (Fig 2 (b)), due to the smaller spacing between the heat sources. Consequently, larger temperature changes take place in the proximity of the basement. In effect, the maximum change in temperature computed at the back of the right-hand side wall is of $1.6^{\circ} \mathrm{C}$ and $2.0^{\circ} \mathrm{C}$ for BHEs and THPs, respectively. Without the correction factor $T^{*}$, these values increase by a substantial amount $(22 \%$ and $38 \%$, respectively). After one year of operation, the temperature change within the VHE fields is equal to zero, since a balanced load was applied. However, close to the wall, the temperature has reduced by approximately $50 \%$ in the case of BHEs and only by $17 \%$ for THPs. Indeed, due to the time-dependent nature of heat propagation, the temperature close to the wall increases even after the commencement of heat extraction, reaching maximum values of $2.0^{\circ} \mathrm{C}$ and $2.8^{\circ} \mathrm{C}$, for BHEs and THPs, respectively.

The changes in pore water pressures are substantially different for the case of BHEs and THPs, as depicted in Fig. 2 (c) and (d), respectively. These depend on both the changes in temperature (where an increase in temperature leads to compressive excess pore water pressures) and the geometry of the VHE field. In the case of the BHEs, largest changes in pore water pressures, of $240.0 \mathrm{kPa}$, are calculated at the bottom of the Lambeth Group Clay, due to its lower permeability (see Eq. 1). At the back of the wall, a maximum change of $15.7 \mathrm{kPa}$ is registered, with this value increasing to $17.6 \mathrm{kPa}$ when $T^{*}$ is not applied. Clearly, since larger temperatures are evaluated for the case of THPs, larger changes in pore water pressures are computed in the proximity of the wall. Within the group of THPs, the maximum change is about $170.0 \mathrm{kPa}$, which takes place at a depth of $2 / 3 \mathrm{H}$. This leads to significant changes in pore water pressures at the back of the wall: $44.0 \mathrm{kPa}$ when $T^{*}$ is applied and $55.0 \mathrm{kPa}$ when this correction factor is not considered. After one year of operation, the pore water pressures have reduced both as a consequence of the heat extraction (which leads to the development of negative excess pore water pressures) and the consolidation process. The reduction is more pronounced in the case of THPs, where it decreases by $50 \%$, whereas a $20 \%$ reduction is evaluated for the analysis simulating BHEs. 


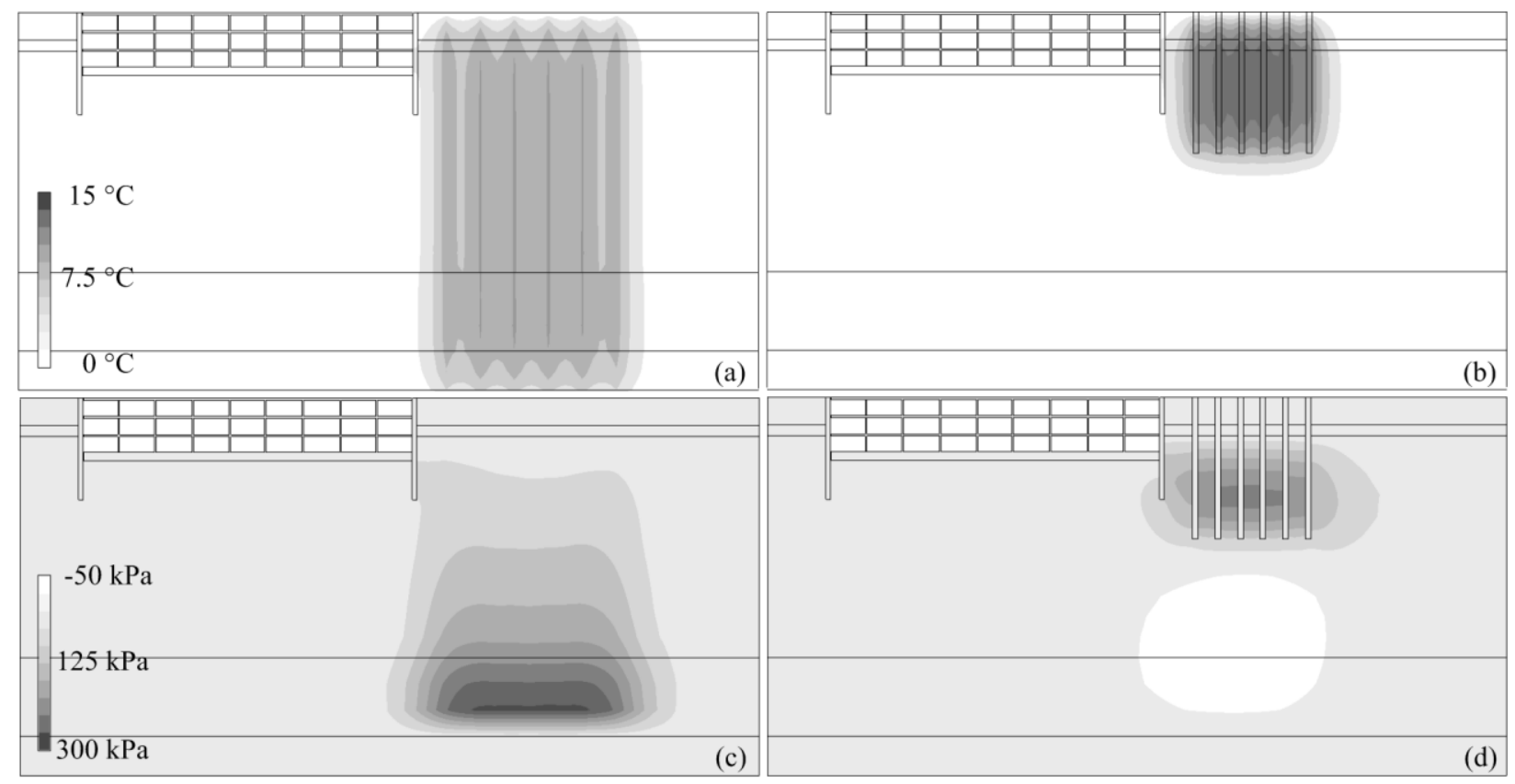

Fig. 2. Contours of temperature changes for cases (a) BHE T* and (b) THP T* and contours of excess pore water pressures for cases (c) BHE T* and (d) THP T* after six months of heat injection

\subsubsection{Ground movements}

Ground movements are induced by volumetric changes caused by thermal soil expansion and excess pore water pressure generation and dissipation. An increase in temperature leads to the expansion of the soil mass. Equally, compressive excess pore water pressures result in soil swelling. Fig. 3 (a) and (b) show the vertical movements registered at the ground surface behind the right-hand side wall at the end of the periods of heat injection and extraction for BHEs and THPs, respectively. Although temperatures are lower for the analyses simulating the presence of BHEs, the vertical ground movements are significantly larger when compared to those computed with THPs. In the former case, a larger volume of soil undergoes changes in temperature and hence the total vertical displacement is larger. Indeed, after six months of heat injection, a maximum heave of $17.0 \mathrm{~mm}$ is registered at the centre of the BHE field, whereas, close to the wall, the ground moves up by $9.2 \mathrm{~mm}$. Conversely, for the case of THPs, the vertical movements close to the wall are limited to $3.2 \mathrm{~mm}$. The analyses without $T^{*}$ compute larger displacements in both cases, i.e. $23 \%$ for BHEs and $40 \%$ for THPs.

During the heat extraction season, the soil undergoes contraction. A much larger change is observed for the case of BHEs, where the ground above the BHE field has settled to $3.7 \mathrm{~mm}$ below its original value, hence a change of $20.7 \mathrm{~mm}$ occurred in a single season. For the analysis without $T^{*}$, seasonal ground movements of $25.0 \mathrm{~mm}$ are computed. At the back of the wall, the change is of about $10.0 \mathrm{~mm}$ and $12.0 \mathrm{~mm}$, with and without $T^{*}$, respectively. On the other hand, smaller changes in ground movements are registered for the analysis involving THPs, where close to the wall these are limited to $3.0 \mathrm{~mm}$ and $4.0 \mathrm{~mm}$, for the analyses with and without $T^{*}$, respectively.
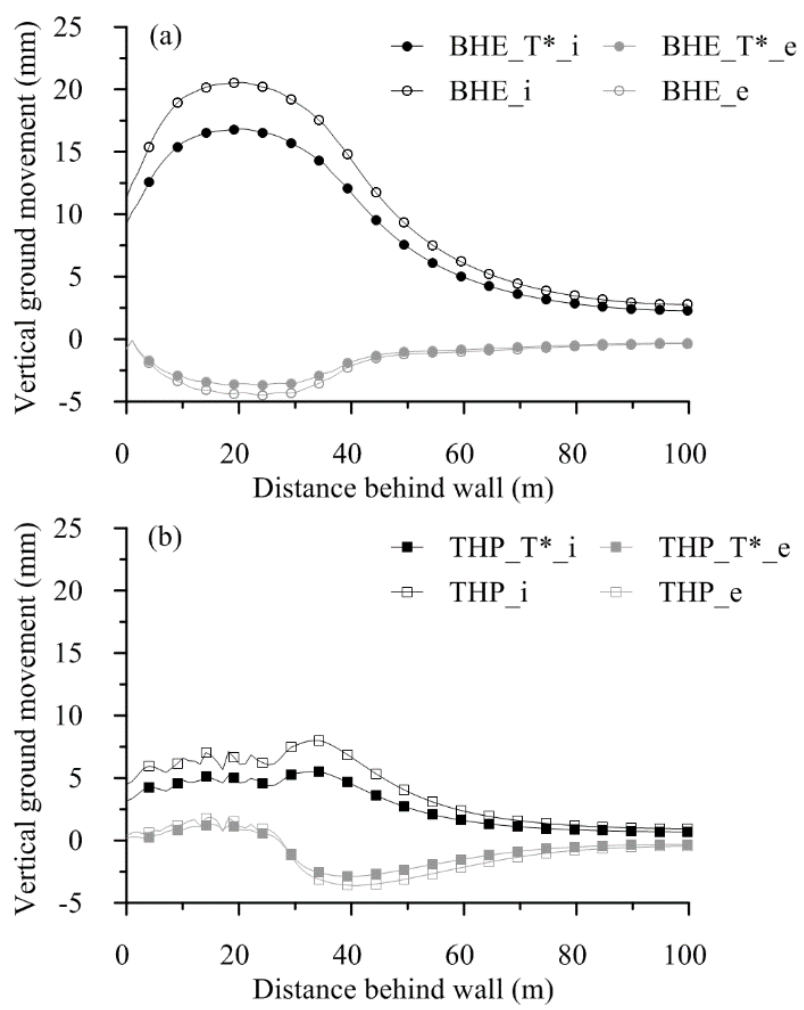

Fig. 3. Vertical surface movements (a) BHEs and (b) THPs

\subsection{Wall response}

\subsubsection{Wall movements}

Fig. 4 (a) depicts the computed horizontal displacements of the right-hand side wall after 6 months of heat injection and after 6 months of heat extraction. At the end of the heat injection period, the wall moves towards the 
excavation for all the analysed cases. The wall next to the BHEs moves almost uniformly, bending slightly at the position of the base slab (10.5 m depth). On the other hand, for the case simulating the presence of THPs, it can be observed that the bottom part of the wall experiences considerably larger displacements than the top part. This is due to temperature changes with depth being less uniform, with a clear peak at around the mid-depth of the pile group (see Fig. 2), which is at a similar level as the bottom part of the wall. The maximum displacement recorded in the analysis involving BHEs occurs at the top of the wall and is equal to $5.9 \mathrm{~mm}$ and $7.0 \mathrm{~mm}$ with and without $T^{*}$, respectively; for the wall next to THPs, the bottom part moves by a maximum of $5.2 \mathrm{~mm}$ and $7.3 \mathrm{~mm}$, respectively with and without $T^{*}$. It should be noted that these movements are much larger than temperature induced horizontal movements computed for walls that are used as heat exchanger, e.g. [6]. During the heat extraction season, the wall moves towards the retained side as a consequence of soil contraction triggered by the cooling of the ground. After 6 months of heat extraction, in all cases, the bottom part of the wall experiences larger displacements than the top part: a maximum seasonal movement of the toe of $6.1 \mathrm{~mm}$ and $8.3 \mathrm{~mm}$ is calculated for BHEs and THPs, respectively. The seasonal movement increases by $21 \%$ and $38 \%$ when $T^{*}$ is not considered.

The vertical displaced shape is shown in Fig. 4 (b). The vertical movement is due to both the thermal expansion/contraction of the heated soil mass and of the wall itself as it undergoes changes in temperature. At the end of the heat injection season, largest vertical wall movements, of $9.3 \mathrm{~mm}$, are calculated for the analysis involving the field of BHEs and a larger downward movement is observed at the end of the heat extraction period for this analysis, where the top of the wall moved down by $10.0 \mathrm{~mm}$ during this season. The wall installed next to the field of THPs moves up by a maximum of $3.2 \mathrm{~mm}$ at the end of the period of heat injection, whereas at the end heat extraction season it moved down by 3.0 $\mathrm{mm}$. The analyses without $T^{*}$ registered higher displacements $(22 \%$ and $40 \%$ for BHEs and THPs, respectively) and larger seasonal changes ( $22 \%$ for BHEs and $36 \%$ for THPs).

\subsubsection{Structural forces}

The changes in axial force and bending moment are shown in Fig. 5 (a) and (b), respectively.

After six months of heat injection, the thermal expansion of the soil leads to a mechanical expansion of the wall, inducing tensile axial forces. As previously observed, larger temperatures and excess pore water pressures are recorded in the case of THPs, contributing to a larger volumetric soil expansion next to the wall. Thus, for this case, considerably larger axial forces are calculated when compared to the analyses involving BHEs. The maximum axial force at the end of the heat injection season is $200.0 \mathrm{kN} / \mathrm{m}$ for THPs (which increases to $250.0 \mathrm{kN} / \mathrm{m}$ for the analysis without $T^{*}$ ) and $86.0 \mathrm{kN} / \mathrm{m}$ for BHEs (which increases to $96 \mathrm{kN} / \mathrm{m}$ for the analysis without $T^{*}$ ). Once heat extraction commences and the soil contracts, the tension within the wall reduces reaching values of less than $50 \mathrm{kN} / \mathrm{m}$ at the end of the heat extraction period for all cases.

The changes in bending moment are also larger for the analyses simulating the presence of THPs. As previously discussed (see Fig. 4 (a)), for this case the wall deflects more, leading to a larger bending moment, reaching a maximum of $210.0 \mathrm{kNm} / \mathrm{m}\left(290.0 \mathrm{kN} / \mathrm{m}\right.$ without $\left.T^{*}\right)$ at the position of the base slab. A smaller bending moment of $100 \mathrm{kNm} / \mathrm{m}$ is computed for the case with BHEs, with only a marginal effect of $T^{*}$ being observed. At the end of the heat extraction season, the bending moments change sign as the wall bends in the opposite direction. However, the magnitude of bending moment at this time instant is considerably smaller.
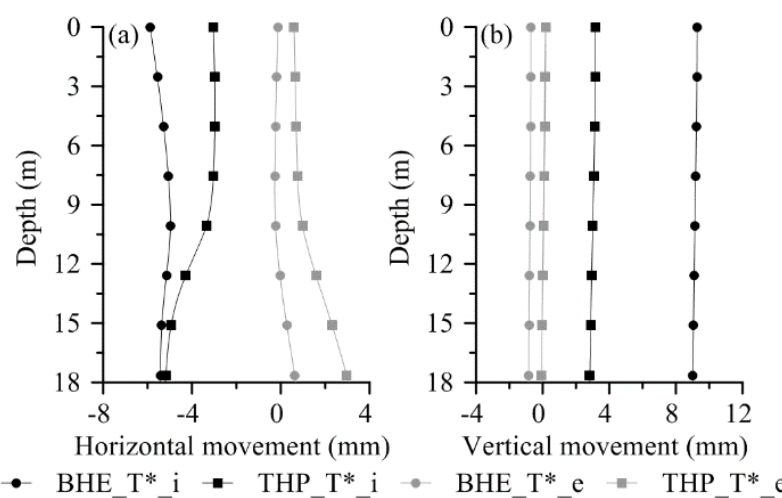

Fig. 4. Wall movements (a) horizontal displaced shape and (b) vertical displaced shape

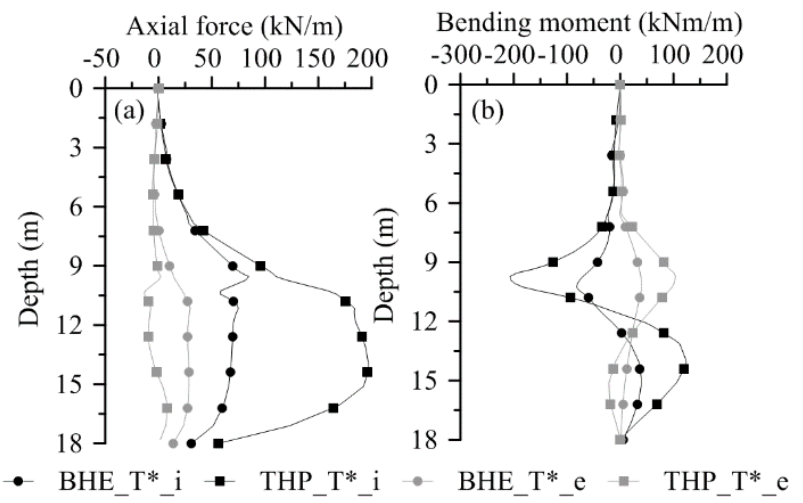

Fig. 5. Changes in structural forces (a) axial force and (b) bending moment

\section{Conclusion}

In this paper, the thermo-mechanical behaviour of a retaining wall installed in the proximity of two different fields of vertical heat exchangers (VHEs) was investigated by performing fully coupled thermo-hydromechanical 2D plane strain finite element analyses. Two different configurations of VHEs were modelled, namely a group of $6 \times 6$ borehole heat exchangers (BHEs) and a pile group consisting of $6 \times 6$ thermo-active piles (THPs). One year of operation was simulated, with balanced heat 
extraction and injection, each over a period of six months. An appropriate equivalent heat load to account for the two-dimensional nature of the analyses was applied and results with the correction factor $T^{*}$ proposed by [16] are compared to those obtained with the conventional approach whereby the heat flux is simply divided by the out-of-plane spacing between VHEs. The use of the correction factor $T^{*}$ was deemed fundamental in the performed analyses since [16] showed that its use leads to a more accurate estimate of the temperature field in 2D plane strain analyses.

This study shows that VHEs installed in proximity of underground structures may have a significant effect on their mechanical response. The results demonstrate that considerable ground movements and changes in pore water pressures take place due to temperature changes caused by the operation of the VHEs. The magnitudes depend on both the value of the induced change in temperature as well as the size and configuration of the field of VHEs. Larger temperatures were computed for the case of THPs due to the smaller spacing between the heat sources. Consequently, larger excess pore water pressures and horizontal soil movements were calculated. Conversely, considerably larger vertical ground movements were registered in the case of BHEs, given the large volume of soil undergoing changes in temperature.

As a result of the observed ground movements, the analysed diaphragm wall was subjected to substantial movements and forces. Vertical wall movements of up to $9.3 \mathrm{~mm}$ and $3.2 \mathrm{~mm}$ were evaluated for the cases involving BHEs and THPs, respectively. The horizontal displaced shapes differed between the two cases, with a larger wall deflection (movements of the toe up to $5.2 \mathrm{~mm}$ ) being experienced by the wall next to the THPs leading to a larger change in bending moments (about $210.0 \mathrm{kNm} / \mathrm{m}$ ). Equally, the change in axial forces was larger in the case of THPs, reaching a maximum tensile change of $200.0 \mathrm{kN} / \mathrm{m}$. It was also observed that the rate at which transient phenomena take place was larger for the analyses simulating THPs, which predict larger seasonal changes in forces and horizontal movements.

Modelling the equivalent heat load without the application of the correction factor $T^{*}$ led to higher predicted changes in temperature and consequently larger structural movements and forces. After 6 months of heat injection, the analyses without the correction factor $T^{*}$ predicted between $10 \%$ and $20 \%$ larger movements and forces for the structure next to BHEs, while an even larger difference, between $25 \%$ and $40 \%$, was computed for the case involving THPs. A visible effect was also observed at the end of the subsequent heat extraction season, where larger seasonal changes occurred for the analyses without $T^{*}$.

In conclusion, the obtained results demonstrate that ground heat exchangers can have a significant impact on adjacent structures. Therefore, temperature changes have to be carefully evaluated and geotechnical analyses are required to verify the long-term safety and serviceability of any nearby structures.
The $\mathrm{PhD}$ programme of the first author is sponsored by the Department of Civil and Environmental Engineering, Imperial College London, through a Skempton Scholarship.

\section{References}

1. M. Antics, R. Bertani, B. Sanner, Proc. of the Europ. Geoth. Cong. 2013, Pisa, Italy (2013)

2. R. G. Campanella, J. K. Mitchell, ASCE J. Soil Mech. Found. Eng. Div. 4 (1968)

3. H. M. Abuel-Naga, D. T. Bergado, A. Bouazza,. Eng. Geol., 89, 144-154 (2007)

4. P. J. Bourne-Webb, B.Amatya, K. Soga, T. Amis, C. Davidson, P.Payne, Geotechnique, 59, 237-248 (2009)

5. K. A. Gawecka, D. M. G. Taborda, D. M. Potts, W. Cui, L. Zdravkovic, M. Haji Kasri. Proc. of the Inst. Civ. Eng. Geotech. Eng., 170(3), 1-19 (2017)

6. P. J. Bourne-Webb, T. M. Bodas Freitas, R. A. Da Costa Gonçalves, Energy Build., 125, 130-141 (2016)

7. D.Sterpi, A. Coletto, L. Mauri, Geomech. Energy Environ., 9, 1-20 (2017).

8. E. Sailer, D. M. G. Taborda, L. Zdravković, D. M. Potts, Comput. Geotech., 109, 189-203 (2019)

9. D. M. Potts, L. Zdravković, Finite element analysis in geotechnical engineering: Theory. (Thomas Telford, London, 1999)

10. W. Cui, D. M. Potts, L. Zdravković, K. A. Gawecka, D. M. G. Taborda, Comput. Geotech., 94, 22-30 (2018)

11. L. A. Wood, A. J. Perrin, Geotechnique, 34(4), 563-579 (1984)

12. E. Sailer, D. M. G. Taborda, L. Zdravković, D. M. Potts, Proc. of NUMGE2018 - IX Europ. Conf. on Numer. Meth. Geotech. Eng., Porto, Portugal (2018)

13. D. M. G. Taborda, D. M. Potts, L. Zdravković, Comput. Geotech., 71, 180-194 (2016)

14. B. Mantell, Final Year Project Report, Dept. of Civ. And Env. Eng., Imperial College London (2017)

15. VDI 4640 Part 1, Thermal use of underground (2010)

16. E. Sailer, D. M. G. Taborda, L. Zdravković, Renewable Energy, 118, 579-590 (2018)

17. F. Dupray, L. Laloui, \& A. Kazangba, Comput. Geotech., 55, 67-77 (2014) 